\title{
Improving the identity of historic city by considering hydraulic infrastructure (the case study: Qazvin city)
}

\author{
Nasim IRANMANESH, Islamic Azad university west Tehran branch, \\ department of Architecture; Iran
}

\section{Abstract}

Recently the importance of maintaining of historic identity of the cities is an obvious matter in restoration of a city. Each city depends on its cultural perception and its wealth, tries to reserve and repair its cultural heritage.

This matter has been done in many cities in the world and many historic urban fabrics have been restored and rehabilitated to be visited by many tourists to enjoy their atmosphere and physical and spiritual features.

Iran is a country with limited water resources but in spite of this fact there are many ancient civilizations and old cities with valuable urban fabrics in them which have intellectual irrigation.

The water of most cities of Iran mostly harvested from underground water by a technic which is called Qanat which irrigate city and farms. Water supplement in urban fabric and locating the hydraulic structure in cities had an important effect in forming the city which this impact shouldn't be ignored in repairing or rehabilitation of urban fabric.

In the other word hydraulic infrastructure of historic cities of Iran in hot and dry region is an important factor which shouldn't forget during planning for rehabilitation. The route of water either underground route or surface water and also hydraulic structures which have been located in the path of water should be preserved.

The case study is Qazvin city which its historic hydraulic infrastructure and hydraulic structures had an important effect in forming the city.

\section{Keywords}

hydraulic infrastructure, urban restoration, cultural heritage, Qanat 


\section{Introduction}

Iran is an ancient country with an old civilization. Most parts of this country have hot and dry climate with a limited source of water. But Iranians have overcome with this problem by harvesting underground water and irrigate their settlement by this water. In Iran water harvested mostly by an intellectual technique which is called Qanat. Qanat brings water of alluvial fans from far distances to settlements. The water supplement in these city followed from the underground or surfaced net of water. The historical water supplement of Qazvin city had an important and direct effect on morphology of city. In the other word the morphology of city was formed according the water resources of this city and placing the hydraulic structures obeyed the path of water in cities as well. This paper discusses about the effect of water supplement on physical form of the historic area of city and deduces that how any rehabilitation planning can't be success without considering the its historic supplement of water in Qazvin city.

\section{A brief explanation about Qazvin city and its water resources}

The case study of this research is Qazvin city a historical city in Iran with a rich traditional urban planning and architecture which have been shaped during different eras.

\subsection{Qazvin city and his historic water supplement}

Iran has been located in hot and dry region and limitation of water is always a big problem of this country. In spite of this serious problem Iran is an old country with an ancient civilization which can be survived by harvesting underground water by an intellectual technique which is called "Qanat" or "Kariz".

Actually in most parts of Iran there is a "Karizian civilization "which has been appeared and survived by this technique of harvesting water.

Qazvin city is an Iranian city which has been located nearly in north of Iran. This city is an ancient city with a rich history but with few sources of water. This city was the capital of Iran four hundred years ago and after that it was an important city in commercial activities so during these eras Qazvin needed more water and harvested this water by Qanats.

Water resources of Qazvin included two main seasonal rivers and some wells which earned underground water, after growing the city and its population water was earned by Qanat which some of them are still alive and have water. 


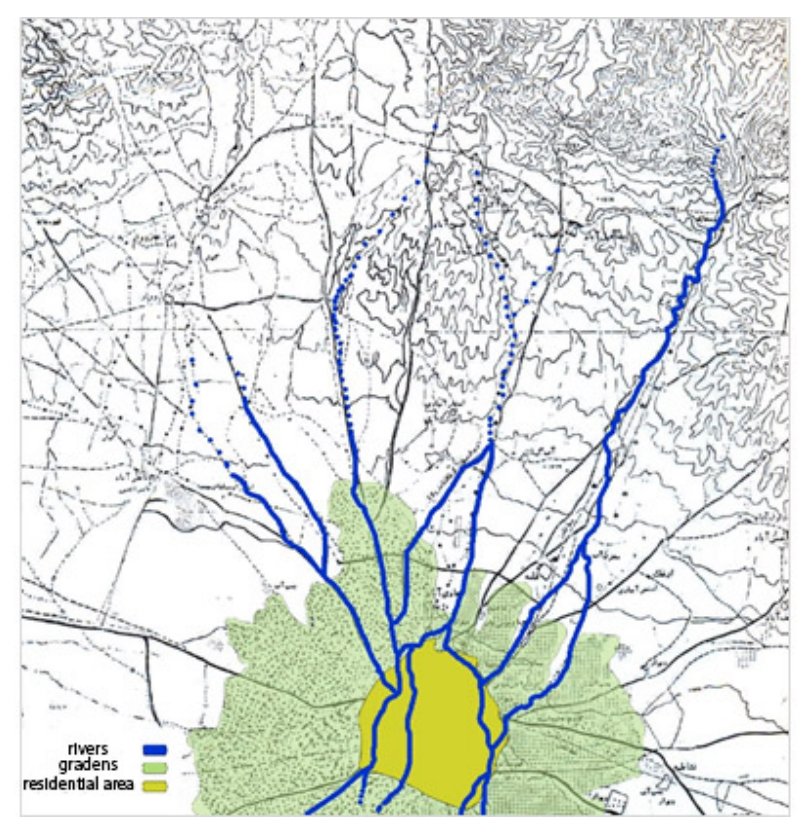

Figure 1 -Old location of Qazvin city (ancient garden whole around the city and seasonal rivers)

The system of Qanat included a horizontal corridor which brings water of alluvial fans toward the settlements. The structure of Qanat consists of a mother well which digs in an aquifer and transfers the water of this well by a horizontal corridor to the destination. To build this horizontal corridor a series of wells is needed to help digging the corridor and be able to maintain the Qanat (figure 1).

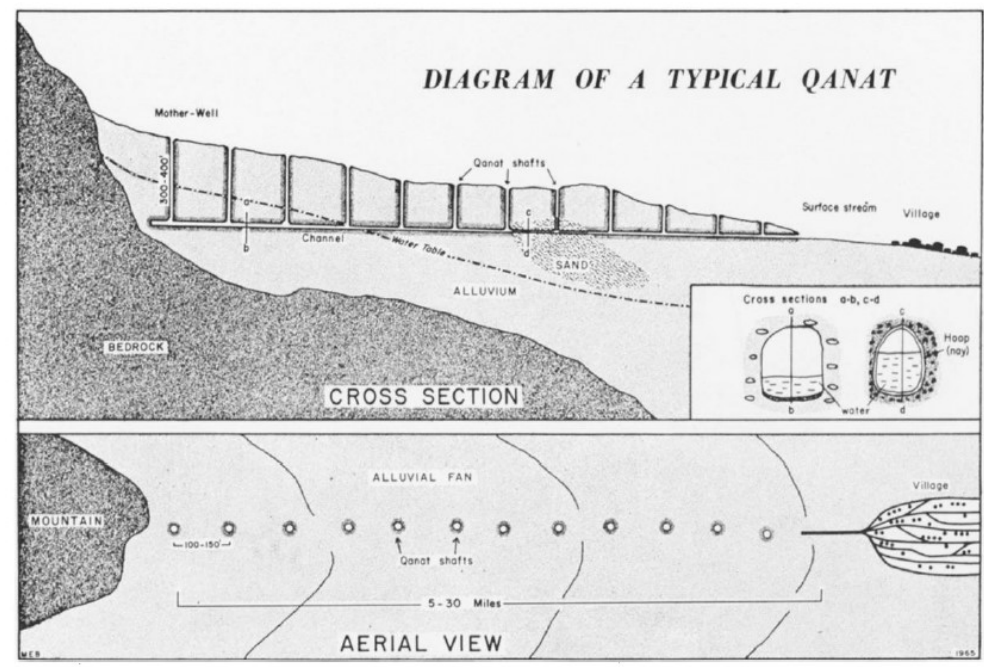

Figure 2: the section and plan of Qanat (source: English) 


\section{Traditional hydraulic structures in Iran}

Water was used in cities for various purposes such as drinking, washing and irrigation. There were several hydraulic structures to meet each function, Iranians built bathes, water reservoirs, ice houses and other buildings that each of them was used for saving water or washing. Hydraulic structures of Iran were built very intellectually and these structures were mostly similar in most parts of Iran (dry and semi dry region of Iran). Here is the brief explanation of hydraulic structures of Qazvin city.

\subsection{Historical hydraulic structures in Qazvin city}

Traditional hydraulic structures in Iran were mostly included different structures such as: Traditional bath, water mill, ice house, wash house, water reservoir and "Payab" or "Akhoreh"

The brief explanation of each structure is:

a- Traditional bath: Iranian society has a great consideration for individual cleaning and bath because of the religious belief. Qazvin city had numerous bathes because of this reason as well.

b- Water mill: as it was mentioned Qazvin has two main seasonal rivers which 27 watermills were located on them to provide flour for the citizens.

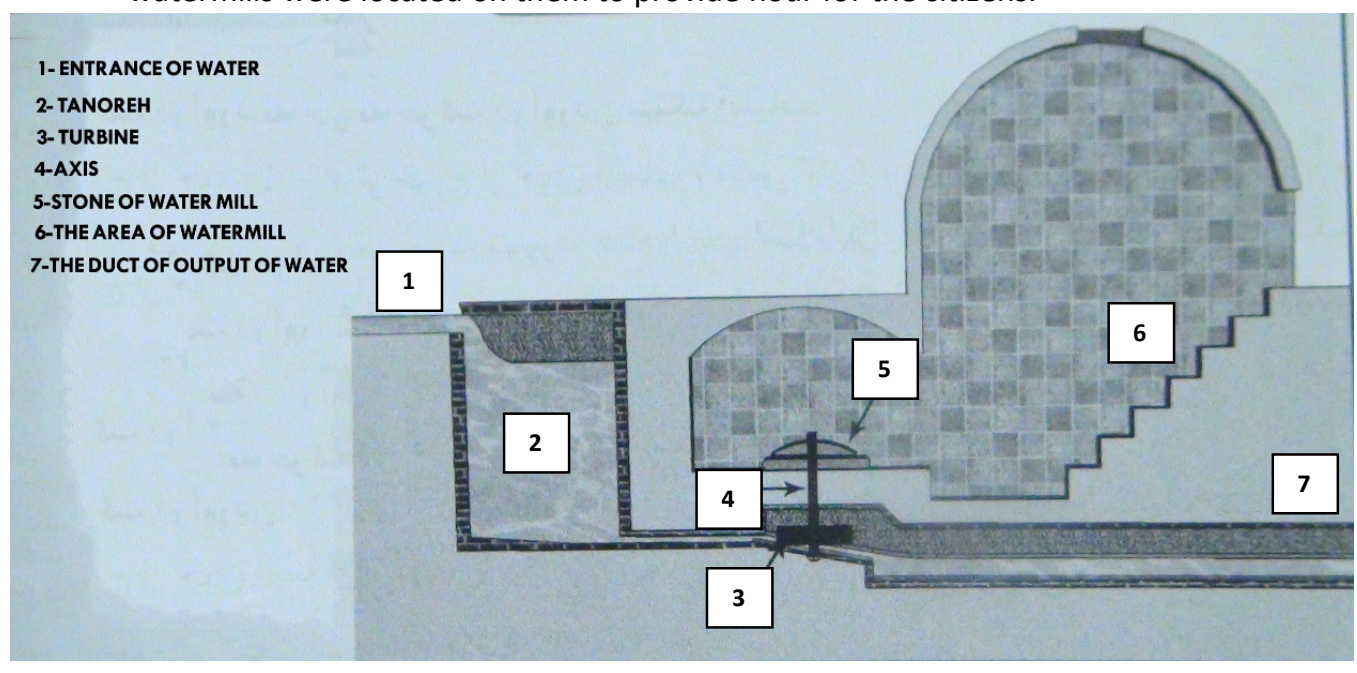

Figure 3. section of a watermill in route of Qanat (source:Semsar Yazdy)

c- Natural ice house: in past time ice was produce by a special technique, it means that water was frozen in shallow pools in winter and the provided ice was stored in huge structures which nearly were similar with water reservoirs and during summer this ice was taken from these reservoirs and was consumed.

d- Wash house: citizens needed water to wash their cloth and dishes and there were two wash houses in Qazvin for women to wash cloth or dishes. 
e- Water reservoir: water in Qazvin was very limited and fresh water should be saved in public or private water reservoir. Public water reservoir were huge buildings which its tank was dug in the earth and covered by a doom or vault.

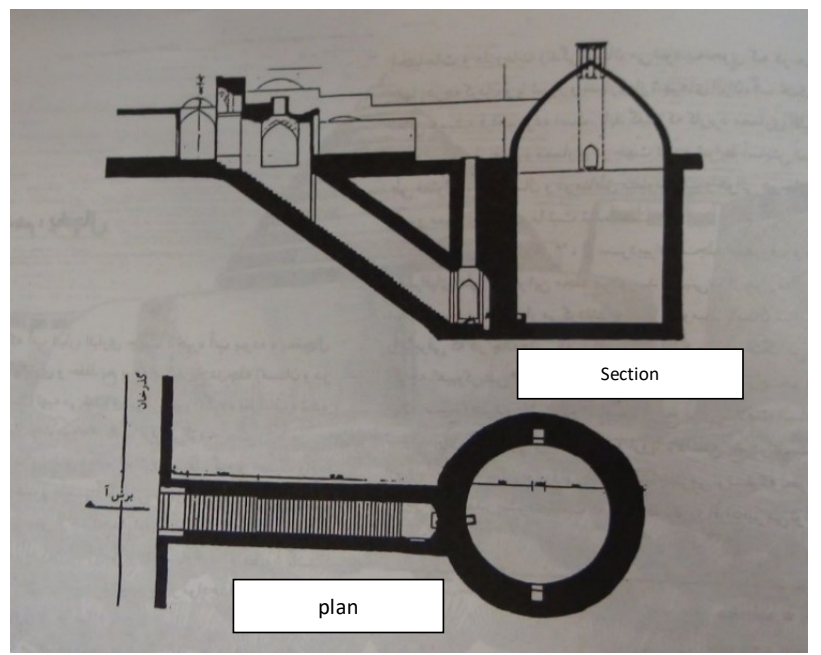

Figure 4: section of a water reservoir in Kashan city (source: Ghobadian)

f- Payab or Akhroh: this structure is an access way to reach the underground water of Qanat. Actually it is a stepped way that reach to the water of Qanat which flowed underground. In Qazvin city people called it "Akhoreh". All the mentioned structures were irrigated by the water of Qanat and location of them were determined by the path of water of Qanat.

This structures were located directly on the path of Water which flowed on the ground or underground. In some case water were lead to these structures by a stream or by pipes and a person who was called "Mirab" was responsible to be supervisor on diving water between hydraulic structures and houses and other buildings. 


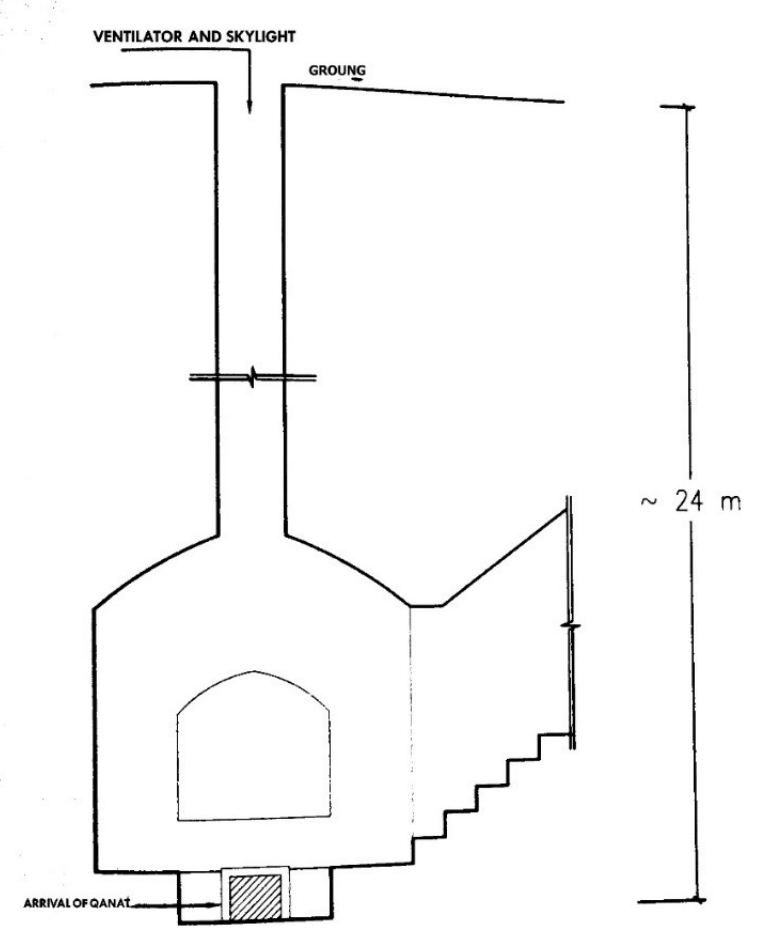

Fig 5. Section of a Payab (source:semsar Yazdy)

\subsection{The effect of traditional water supplement in historical fabric of Qazvin}

It is obvious that the traditional water supplement in historic area of Qazvin had an important effect in its morphology.

Qazvin is surrounded by flourish gardens which has more than one thousand years. This gardens are irrigated once or twice in a year by two seasonal rivers Dizaj and Aranzak.

City of Qazvin was irrigated by eight Qanats which mother well of all of them are in the north of city.

The path of underground water and surface water mostly determined the net of roads and lanes in cities. Water flows in lanes because it was mostly belonged to all citizens and a person who is responsible for dividing water (in Persian "Mirab") distribute water between citizens according their ownership of water. Location of hydraulic structures were determined according the path of water as well. Water reservoir, bath, ice house, wash house,"Akhoreh" and so on were located according the path of water of Qanats or rivers.

For example, the location of great mosque was determined in a way that an "Akhoreh" can been built for people to be able to wash and to be ready to do religious porpuses. 
So the priority in locating the great mosque was the accessibility of prayers to the water of Qanat. This role was for the other hydraulic structure as well. Their locations were according the path of Qanats.

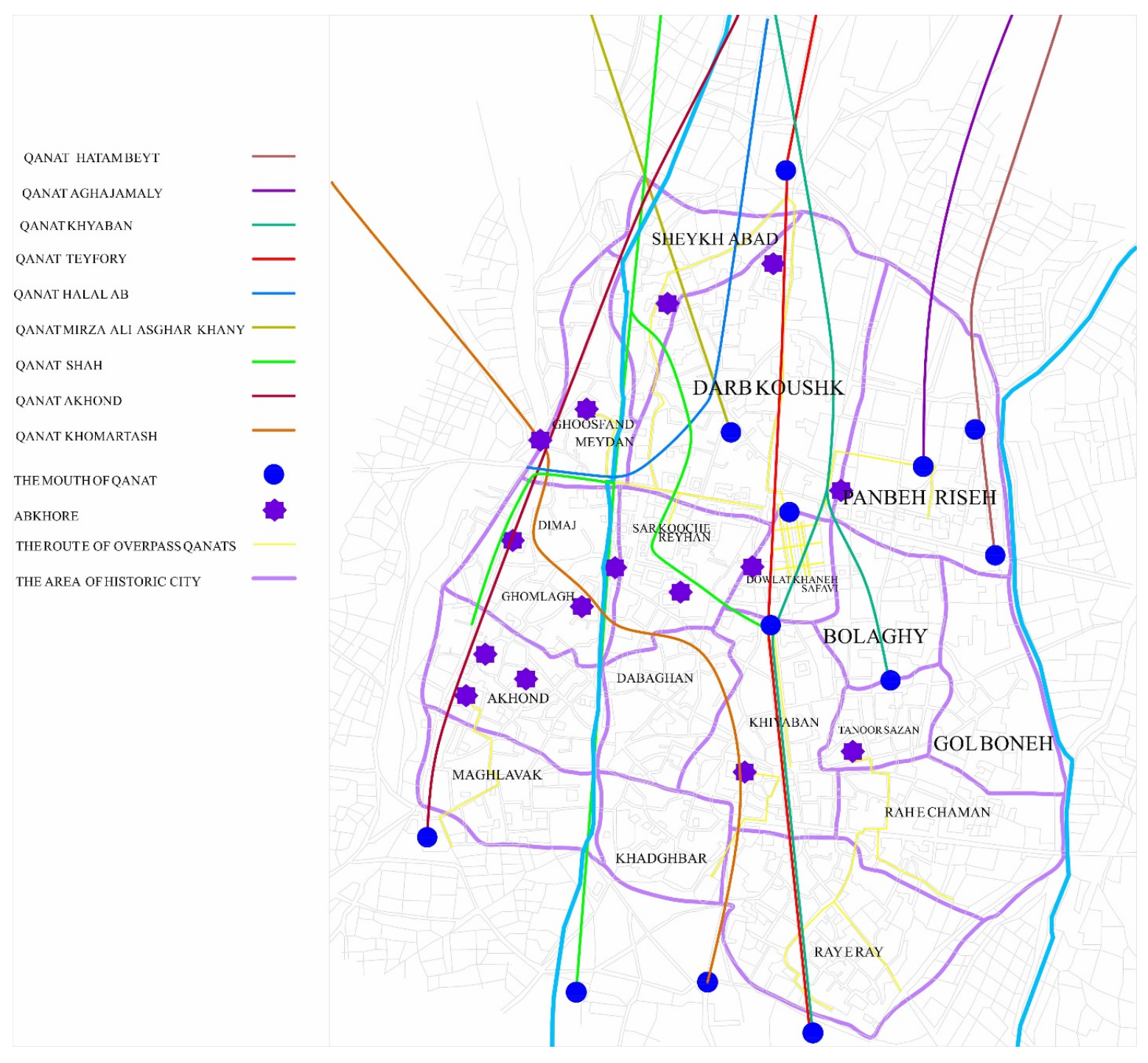

Map 1: The route of water in districts of Qazvin city

\section{Conclusion}

Water is the main factor in forming a settlement in hot and dry region of Iran. Iranian harvested this valued element from underground aquifer and build their 
cities and villages. Water infrastructure in such cities has the main role in morphology of city again.

Water flowed mostly in common lanes in cities and hydraulic structures and other buildings were placed according the path of water. This fact has an important effect in morphology of cities. Actually it should be said that initially the road network had been formed and after that its land use and then lots and its dimensions were determined during the forming of cities and villages.

So if we want to have any restoration activities or rehabilitation or any similar activities in reviving identity of historical cities of Iran we should consider water infrastructure of them first or at least simultaneously. In the other word in historic cities water infrastructure can't be ignored in rehabilitation activities and if we aim to revive the real identity of these cities water infrastructure and its features is a main element in that cities.

But unfortunately this fact mostly neglected by architect and urban planners during restoration activities in historical cities of Iran.

But this aspect (traditional water supplement) is an important part of the identity of an Iranian historical city in hot and dry region. Carful and technical restoration of water infrastructure and hydraulic structures of a historic city causes a more real historic city with its real features and can attract tourists which are interested to an Iranian city with its amazing characteristics.

\section{References}

1- Alehashem ,Ayda ( 2018) "Rethinking the multidimensional integration between water networks and urban structures in Iran" , International workshop water and city hydraulic systems and urban structures, Yazd , Iran

2- Beaumont, Peter (2003) The qanat : a means of water provision from groundwater sources, The Middle East Center, school of oriental and African studies

3- Bonine, Micheal (2003) Qanat, Kariz and Kattara, The Middle East Center, school of oriental and African studies

4- Bonine, Micheal (1979) TheMorphogenesisof Iranian cities, Annals of the Association of American Geographers, Vol. 69, No. 2 ,Jun.

5- English, Paul Ward (1988) Qanats and Lifeworlds in Iranian Plateau Villages, University of Texas, Austin

6- English, Paul Ward (1968) The origin and spread of Qanats in the old world, Proceedings of the American Philosophical Society, Vol. 112, No. 3 (Jun. 21,)

7- Liliey, Keith (2000) Mapping the medieval city: plan analysis and urban history, urban history no.27,1, Cambridge university press 
8- Noghsan Mohammadi, Mohammad Reza (2018) The influence of the underground water system on the urban morphology of traditional city of Yazd, International workshop water and city hydraulic systems and urban structures, Yazd

9- Oliveira vitor (2016) Urban morphology an introduction to the study of the physical form of cities, Springer

10- Roaf, S (2003) settlement form and qanat routes in the Yazd province, Qanat, Kariz and Kattara, The Middle East Center, school of oriental and African studies

11- Semsar yazdi , Samira Askarzadeh (2007) A historical review on the Qanat and historic hydraulic structures of Iran since the first millennium B.C , International History Seminar on Irrigation and Drainage , Tehran-Iran May 2-5

12- Whitehand.J.W.R (2001) British urban morphology : the conzenian tradition , urban Morphology 